\title{
Isolation of Cellulose-Degrading Actinomycetes and Evaluation of their Cellulolytic Potential
}

\author{
Yugal Kishore Mohanta \\ Department of Biotechnology, North Orissa University, Baripada, 757003, India \\ *Corresponding Author: ykmohanta@gmail.com
}

Copyright (C) 2014 Horizon Research Publishing All rights reserved.

\begin{abstract}
Nine isolates of cellulose-degrading Actinomycetes were isolated from different sediment samples from the Bhitarkanika Mangrove Forest. Cellulase and hydrolytic activity was confirmed with clear zone around the colony on basal salt agar medium using Congo Red. The enzyme assays for two enzymes, filter paper cellulase (FPCase), and carboxymethylcellulase (CMCase), were examined by methods recommended by the International Union of Pure and Applied Chemistry (IUPAC). The extracellular cellulase activities ranged from $0.266 \pm 0.001$ to $0.734 \pm 0.001 \mathrm{IU} / \mathrm{mL}$ for $\mathrm{FPC}$ and $0.501 \pm 0.014$ to $1.381 \pm 0.024 \mathrm{IU} / \mathrm{mL}$ for CMCase or endoglucanase assay.
\end{abstract}

Keywords Celluloytic Actinomycetes, FPCase, CMCase, Bhitarkanika Mangrove Forest

\section{Introduction}

Cellulose is the most abundant renewable carbon source available on the earth for production of commercial value added feedstock chemicals, when converted efficiently to monomeric D-glucose units [1]. The availability of cellulose makes it an attractive and useful raw material for producing many industrially important commodity products [2]. From the starting, both chemical and enzymatic hydrolysis has been employed for effective conversion of crude cellulosic biomass into fermentable sugar; make it to be simple to use in different industrial purposes. The old method is currently being employed as most common means for producing mono-saccharides from cellulose. Apart from it, chemical hydrolysis often leads to the accumulation of undesired non-sugar byproducts that poses big problems in recovery of resultant products and use as a cost effective product [3]. On the other hand, enzymatic hydrolysis overrides all such problems and can be used effectively over chemical hydrolysis. It has a great potential of the lower solubility in the aqueous medium [4]. Cellulase enzyme system which completely controls the enzymatic hydrolysis process comprises three classes of soluble extracellular enzymes: (1) 1 , 4- $\beta$-endoglucanase, (2) 1, 4- $\beta$-exoglucanase, and (3) $\beta$-glucosidase ( $\beta$-D-glucoside glucohydrolase or cellobiase). Generally endoglucanase is responsible for random cleavage of internal $\beta-1,4$-glycosidic bonds a long a cellulose chain. Exoglucanase is mostly required for cleavage of the non-reducing end of a cellulose chain and splitting of the elementary fibrils from the crystalline cellulose and $\beta-1$, 4-glucosidase hydrolyses cellobiose and water-soluble cello-dextrin to glucose [5,6]. Synergetic activities of all these three enzymes provide the best result of completely hydrolysis of raw cellulose to glucose [7-9]. Microorganisms are giving an outstanding contribution regarding the synthesis of extracellular cellulase enzymes and are effectively used for the conversion of the cellulosic biomass to simple sugar molecules. Several microorganisms are reported as potential of cellulose productions viz. Actinomycetes, Bacteroides succinogenes, Butyrivibrio fibrisolvens, Clostridium species, Ruminococcus albus, Aspergillus species, Chaetomium species, Fusarium species, Methanobrevibacter ruminantium, Myrothecium species, Penicillium species, Trichoderma species etc. [10,11]. These microorganisms plays vital role as mineralizes of organic matter and thereby influencing the productivity of the marine environment. Cellulase is widely used, due to its potential applicability in various industrial processes such as production of bioethanol $[12,13]$, triphasic biomethanation [14], agricultural and plant waste management $[15,16]$; chiral separation and ligand binding studies [17] etc.

Present work focuses on the isolation of cellulose degrading actinomycetes from a mangrove forest area (sediments and plant decomposed soils) and assessment of its cellulolytic potential.

\section{Materials and Methods}

\subsection{Sample Collections}

An extensive collection of various sediment samples were set up in Bhitarkanika National Park $\left(20^{\circ} 44.387^{\prime} \mathrm{N}\right.$, 
086 52.042") during the Monsoon season (2013).The sediment samples were kept in sterile falcon tubes and after reaching the lab all are kept in $-20{ }^{\circ} \mathrm{C}$ till further processing.

\subsection{Isolation and Screening of Cellulose Degrading Actinomycetes}

Sediment and plant decomposed soil were collected from Bhitarkanika National Park. Soil samples were kept in $70^{\circ} \mathrm{C}$ to eradicate the moisture. One gram of each soil sample was transferred to aliquot of $9 \mathrm{~mL}$ sterile distilled water in sterile test tube. The solution was vigorously haken by vortex mixture at constant speed $4000 \mathrm{rpm}$ for $15 \mathrm{~min}$. The soil suspension was then subjected to serial dilutions up to $10^{-5}$. Each dilution was inoculated in ISP-2 Medium (Yeast extract: $4 \mathrm{~g} / \mathrm{L}$, Malt extract powder: $10 \mathrm{~g} / \mathrm{L}$, Glucose: $4 \mathrm{~g} / \mathrm{L}$, Agar: $18 \mathrm{~g} / \mathrm{L}$ ) in appropriate plate in duplicate. The plates were incubated for 7 days at $28^{\circ} \mathrm{C}$. Pure culture actinomycetes strains are stored in ISP-2 medium at $4^{0} \mathrm{C}$ and Glycerol stock was prepared for future use.

Actinomycetes strains were screened for their ability to produce the hydrolytic enzymes: cellulase in a plate assay method using $1 \%$ carboxymethyl cellulose in a basal salt media, respectively, according to [18] at the incubation period, $0.1 \%$ Congo red solution was added and counterstained with $1 \mathrm{M} \mathrm{NaCl}$ for $15-20 \mathrm{~min}$. The zone of cellulose hydrolysis was appeared as a clear area around the colony.

\subsection{Cellulase Enzyme Production}

The selected BAY isolates were cultured at $37^{\circ} \mathrm{C}$ at 150 rpm in orbital shaker for enzyme production in basal salt media composed of $\mathrm{KH}_{2} \mathrm{PO}_{4} 0.5 \mathrm{~g}, \mathrm{MgSO}_{4} 0.25 \mathrm{~g}$, and gelatin $2 \mathrm{~g}$, distilled water $1 \mathrm{~L}$ and containing Whatman filter paper No.1 ( $0.05 \mathrm{~g} / 20 \mathrm{~mL})$ and at $\mathrm{pH}$ 6.8-7.2. Broth culture after six days of incubation period was subjected to centrifugation at $5000 \mathrm{rpm}$ for $15 \mathrm{~min}$ at $4^{\circ} \mathrm{C}$. The cells and other debris are settled down at the bottom and form the pellet.The cell free supernatant after centrifugation was collected and stored as crude enzyme preparation at $4^{\circ} \mathrm{C}$ for further enzyme assays.

\subsection{Cellulase Enzyme Assays}

Total cellulase activity (FPCase and CMcase) was determined by standard method [18]. Endoglucanase ( $\beta, 1-4$ endoglucanase- EC 3.2.1.4) activity was assayed by measuring the amount of reducing sugar from carboxymethyl cellulose (CMC). The cellulase activity was determined according to the methods recommended by the International Union of Pure and Applied Chemistry (IUPAC) commission on biotechnology [19]. Endoglucanase (CMCase) activity was determined by incubating $0.5 \mathrm{~mL}$ of crude enzyme supernatant with $0.5 \mathrm{~mL}$ of $2 \%$ carboxy methyl cellulose in $0.05 \mathrm{M}$ sodium citrate buffer $(\mathrm{pH} 4.8)$ at $55^{\circ} \mathrm{C}$ for 30 minute. FPCase activity was also determined by incubating $0.5 \mathrm{~mL}$ of crude enzyme supernatant with $1.0 \mathrm{~mL}$ of $0.05 \mathrm{M}$ sodium citrate buffer ( $\mathrm{pH} 4.8$ ) containing Whatman no. 1 filter paper $(50 \mathrm{mg})$. After incubation for an hour at $55^{\circ} \mathrm{C}$, the reaction was terminated by adding $3 \mathrm{~mL}$ of 3 , 5 -dinitrosalicylic acid (DNS) reagent to $1 \mathrm{~mL}$ of reaction mixture. Reducing sugars were estimated spectrophotometrically with 3, 5-dinitrosalicylic acid [20] using glucose as standard. The enzymatic activity of total FPCase and endoglucanase (CMCase) were defined in international units (IU). One unit of enzymatic activity is defined as the amount of enzyme that releases $1 \mu \mathrm{mol}$ reducing sugars (measured as glucose) per $\mathrm{mL}$ per minute.

\subsection{Statistical Analysis}

All data of results are analyzed by the one way ANOVA by SPSS and presented with ( \pm S.D.). Each experiments were carried out independently by taking three replicates. The average mean of results of the three replicates are represented with standard deviations.

\section{Results and Discussion}

Cellulases actively convert cellulose to simple fermentable sugars readily accessible for human consumption and genus Streptomyces is known as the largest producer of cellulases [21]. Extensive research revealed that cellulases produced from Streptomyces sp. are of optimum alkaline $\mathrm{pH}$ and highly thermostable [22]. Besides Streptomyces, several other genera like Micromonospora and Thermobifida are known to be produced recombinant cellulases [23]. A recombinant cellulase with thermal and $\mathrm{pH}$ stability is also reported from Streptomyces thermoviolaceus. This enzyme is highly stable and active in the presence of commercial detergents and other ionic liquids, proves its superiority to the existing commercial cellulases [24]. Cellulase from Thermomonospora fusca has been used for degradation of avicel and cotton [25].

\subsection{Isolation and Screening of Cellulose Degrading Actinomycetes}

Cellulase activity of actinomycetes was carried out by preliminary screening method using the hydrolysis of substrate incorporating in the basal salt medium. The present study is a preliminary characterization of cellulase activities of the strains among the 50 actinomycetes isolated from soil samples of different locations. A total of nine actinomycetes isolates (BAY 41,03,04,40,22,33,23,08 \& 21) found to be positive on screening media (cellulose Congo-Red agar) producing clear zone (Figure 1) indicated the cellulase enzyme activity.

\subsection{Cellulolytic Potential of Actinomycetes}

Actinomycetes are one of the important microbial communities greatly responsible for cellulose degradation of the plant sources. The effect of major environmental factors 
such as temperature, salinity and $\mathrm{pH}$ are found to be important parameters that influence enzyme production and activities [26]. All nine actinomycetes (BAY 41, $03,04,40,22,33,23,08 \& 21)$ isolates are selected for the production of cellulase enzymes and their cellulose degrading potential is estimated. The total cellulase activity ranges from $0.501 \pm 0.014$ to $1.381 \pm 0.024 \mathrm{IU} / \mathrm{mL}$ for endoglucanase while $0.266 \pm 0.001$ to $0.734 \pm 0.001 \mathrm{IU} / \mathrm{mL}$ for FPCase activity. The three actinomycetes isolate BAY 03, 22 \&21 performed highest cellulase activity with compared to the other isolates. Strain BAY 22 exhibited the highest FPCase activity with $0.734 \pm 0.001 \mathrm{IU} / \mathrm{mL}$ while BAY 21 showed highest endoglucanase (CMCase) activity with $1.381 \pm 0.024 \mathrm{IU} / \mathrm{mL}$. Jeffrey and Azrizal reported about the cellulase production from Streptomyces gancidicus, Streptomyces malachitofuscus , Streptomyces stramineus and Streptomyces glomeratus isolated from different locations of Peninsular Malaysia [27]. Till date fungal strains are reported to be the highest cellulase activity among the microorganisms and the fungal species Trichoderma reesei has the highest cellulase activity [28]. Actinomycetes which are also known as filamentous bacteria are very close to fungal characteristics and are showing quite more cellulase activity in comparison to the pure bacterial species. Recently, Gupta et al. [2] studied the bacterial cellulase activities ranged from 0.012 to $0.196 \mathrm{IU} / \mathrm{mL}$ for $\mathrm{FPC}$ and 0.162 to $0.400 \mathrm{IU} / \mathrm{mL}$ for endoglucanase assay. The CMCase value of actinomycetes is higher than activity of CMCase produced from some known natural isolates (expressed per $\mathrm{mL}$ of cell-free culture broth), for example, Cellulomonas sp. (0.0336 U/mL,), Micrococcus sp. (0.0152 U/mL), Bacillus sp. $(0.0197 \mathrm{U} / \mathrm{mL}$,$) , Brevibacillus sp. JXL (0.02 \mathrm{U} / \mathrm{mL}$,), Brevibacillus sp. DUSELG12 (0.02 U/mL), Geobacillus sp. DUSELR7 (0.058 U/mL,), Geobacillus sp. $(0.0113 \mathrm{U} / \mathrm{mL})$, and Bacillus subtilis AS3 (0.07 U/mL) [29-33]. This result was supported by the findings of Howell and Mangat (1978) [34]. The cellulase activities of all isolates are shown in the Figure 2 and Figure 3.

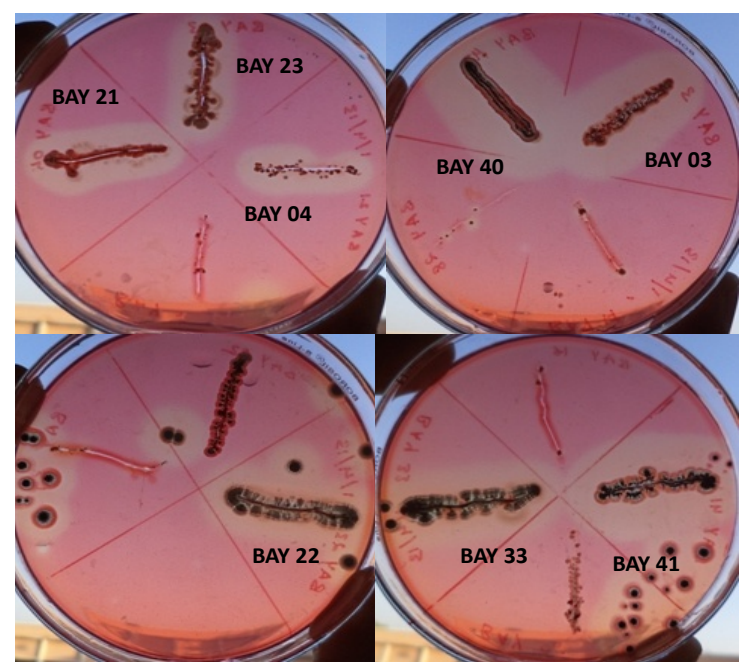

Figure 1. The clearing zone around the BAY colonies confirms the production of extracellular cellulose after $72 \mathrm{hrs}$ of incubation.

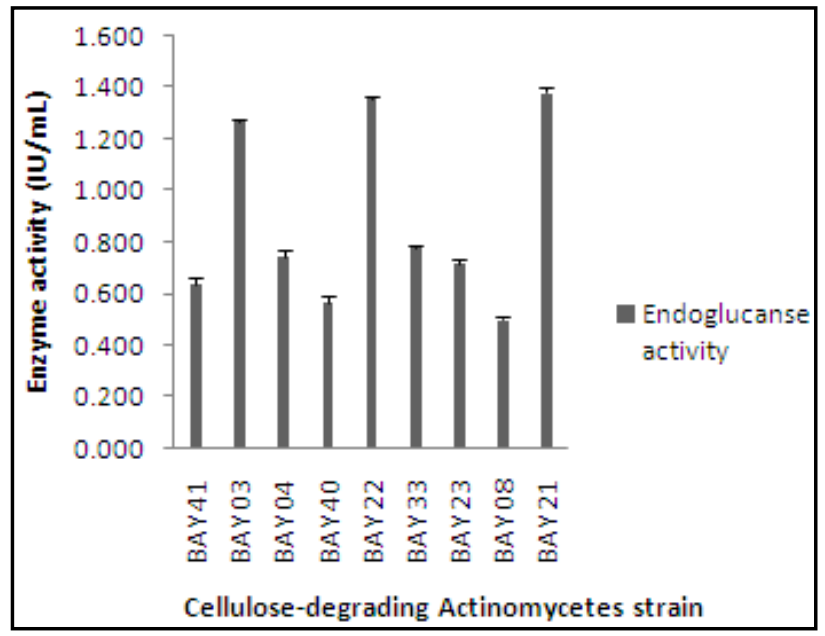

Figure 2. CMCase activity of all BAY actinomycetes strains

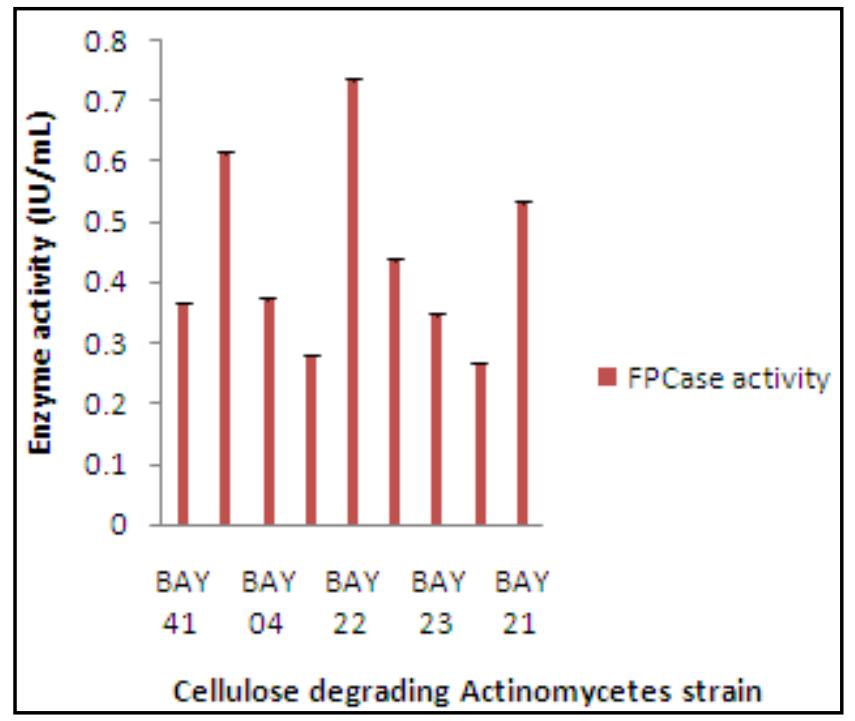

Figure 3. FPCase activity of all BAY actinomycetes strains

\section{Conclusion}

The present study highlighted the potential cellulase activity of strains (BAY 03, $21 \& 22$ ) which can be used for production of biofuel and other industrial products. These cellulase enzymes from actinomycetes can strengthen other microbial cellulase sources from fungal and bacterial cellulase. Further investigations are required to make use of the full potential of these organisms for cellulase production by modern protein engineering technology.

\section{Acknowledgements}

Y.K.M. is grateful to Department of Science and Technology, Govt. of India for providing Junior Research fellowship (DST-INSPIRE fellowship) for continuing doctoral Research. The author is also thankful to PCCF, Govt. of Odisha for giving permission for collecting samples 
from Bhitarkanika National Park.

\section{Abbreviations}

CMCase - Carboxymethylecellulase

FPCase - Filterpapercellulase

\section{REFERENCES}

[1] D. Klemm, B. Heublein, H.P. Fink, A. Bohn. Cellulose: fascinating biopolymer and sustainable raw material. Angew Chemical International Education, Vol.44, 3358-3393, 2005.

[2] P. Gupta, K. Samant, A. Sahu. Isolation of Cellulose-Degrading Bacteria and Determination of Their Cellulolytic Potential. International Journal of Microbiology Volume 2012, Article ID 578925, doi:10.1155/2012/578925.(In press)

[3] M. Sasaki, B. Kabyemela, R. Malaluan, S. Hirose, N. Takeda, T. Adschiri. Cellulose hydrolysis in subcritical and supercritical water. Journal of Supercritical Fluids, Vol.13, 261-268, 1998

[4] N. Trivedi, V. Gupta, C.R.K. Reddy, B. Jha. Detection of ionic liquid stable cellulase produced by the marine bacterium Pseudoalteromonas sp. isolated from brown alga Sargassum polycystum C. Agardh. Bioresource Technology,Vol. 132, 313-319, 2013

[5] J. G. Shewale. Glucosidase: its role in cellulase synthesis and hydrolysis of cellulose.International Journal of Biochemistry, Vol. 14, No. 6, 435-443, 1982.

[6] J. Woodward, A. Wiseman. Fungal and other $\beta$-dglucosidases: their properties and applications. Enzyme and Microbial Technology, Vol. 4, No. 2, 73-79, 1983.

[7] D. D. Y. Ryu, M. Mandels. Cellulases: biosynthesis and applications. Enzyme and Microbial Technology, Vol. 2, No. 2, 91-102, 1980.

[8] D. K. Samdhu, S. Bawa. Improvement of cellulase activity in Trichoderma. Applied Biochemistry and Biotechnology, Vol. 34-35, No. 1, 175-192, 1992.

[9] T. M. Wood. Synergism between enzyme components of Penicillium pinophilum cellulase in solubilizing hydrogen ordered cellulose. Journal of Biochemistry, Vol. 260, $37-43,1989$.

[10] M. A. Milala, A. Shugaba, A. Gidado, A. C. Ene, J. A. Wafar. Studies on the use of agricultural wastes for cellulose enzyme production by $A$. niger. Journal of Agriculture and Biological Science, Vol. 1, 325-328, 2005.

[11] W. H. Schwarz. The cellulosome and cellulose degradation by anaerobic bacteria. Applied Microbiology and Biotechnology, Vol. 56, No. 5-6, 634-649, 2001.

[12] M. M. Ekperigin. Preliminary studies of cellulase production by Acinetobacter anitratus and Branhamella sp. African Journal of Biotechnology, Vol. 6, No. 1, 28-33, 2007.

[13] P. Vaithanomsat, S. Chuichulcherm, W. Apiwatanapiwat.
Bioethanol production from enzymatically saccharified sunflower stalks using steam explosion as pretreatment. Proceedings of World Academy of Science, Engineering and Technology, Vol. 37, 140-143, 2009.

[14] N. Chakraborty, G.M. Sarkar, S.C. Lahiri. Cellulose degrading capabilities of cellulolytic bacteria isolated from the intestinal fluids of the silver cricket. Environmentalist, Vol. 20, No. 1, 9-11, 2000

[15] W. J. Lu, H. T. Wang, Y. F. Nie et al., "Effect of inoculating flower stalks and vegetable waste with ligno-cellulolytic microorganisms on the composting process," Journal of Environmental Science and Health, Part B, Vol. 39, No. 5-6, 871- 887, 2004.

[16] A.Y. Mswaka, N. Magan. Wood degradation, and cellulase and ligninase production, by Trametes and other wood-inhabiting basidiomycetes from indigenous forests of Zimbabwe. Mycological Research, Vol. 102, No. 11, 13991404,1998

[17] A. Nutt, V. Sild, G. Prtterson, G. Johansson. Progress curve as a means for functional classification of cellulases. Europian Journal of Biochemistry, Vol. 258, 200, 1998.

[18] L. Hankin, S. L. Anagnostakis. Solid media containing carboxy methylcellulose to detect $\mathrm{Cx}$ cellulase activity of micro organisms. Journal of General Microbiology, Vol. 98, No. 1, 109-115, 1977.

[19] T. K. Ghose. Mesurnment of cellulase activity. Pure and Applied Chemistry, Vol. 59, 257-268, 1987.

[20] G. L. Miller. Use of dinitrosalicylic acid reagent for determination of reducing sugar. Analytical Chemistry, Vol. 31, No. 3, 426-428, 1959.

[21] H. D. Jang, K. S. Chang. Thermostable cellulases from Streptomyces sp.: scale-up production in a 50-1 fermenter. Biotechnology Letters, Vol. 27, No. 4, 239-242, 2005.

[22] B. E. Jones, A. H. Kleij Wilhelmus, P. Van Solingen, W. Weyler. Cellulase producing actinomycetes, cellulase produced there from and method of producing same. EP 1408108 B1, 2004.

[23] F. Zhang, J. J. Chen, W. Z. Ren et al. Cloning, expression and characterization of an alkaline thermostable GH9 endoglucanase from Thermobifida halotolerans YIM, 90462 T. Bioresource Technology, Vol. 102, No. 21, 10143-10146, 2011.

[24] B. E. Jones, A. H. Kleij Wilhelmus, P. Van Solingen, and W. Weyler. Cellulase producing actinomycetes, cellulase produced there from and method of producing same. US Patent 6566112, 2003

[25] S. P. George, A. Ahmad, M. B. Rao. Studies on carboxymethyl cellulase produced by an alkalothermophilic actinomycete. Bioresource Technology, Vol. 77, No. 2, 171-175, 2001.

[26] S.P. Vinogradova,S.N. Kushnir. Biosynthesis of hydrolytic enzymes during co-cultivation of macro-and micromycetes.Applied and Biochemistry and Biotechnology,Vol.39, 573-575,2003.

[27] L.S.H. Jeffrey, M.R. Azrizal. Screening for cellulase activities in actinomycetes isolated from different locations of Peninsular Malaysia. Journal of Tropical Agriculture and 
Food Science. Vol.35,No1, 153-157, 2007.

[28] Singhania RR, Sukumaran RK, Patel AK, Larroche C, Pandey A. Advancement and comparative profiles in the production technologies using solid-state and submerged fermentation for microbial cellulases. Enzyme Microbial Technology, Vol.46, 541-549, 2010.

[29] G. Immanuel, R. Dhanusha, P. Prema, A. Palavesam. Effect of different growth parameters on endoglucanase enzyme activity by bacteria isolated from coir retting effluents of estuarine environment. International Journal of Environmental Science and Technology, Vol. 3, No. 1, 25-34, 2006.

[30] Y. Liang, J. Yesuf, S. Schmitt, K. Bender, and J. Bozzola. Study of cellulases from a newly isolated thermophilic and cellulolytic Brevibacillus sp. strain JXL. Journal of Industrial Microbiology and Biotechnology, Vol. 36, No. 7, 961-970, 2009.
[31] G. Rastogi, G.L. Muppidi, R.N. Gurram et al. Isolation and characterization of cellulose-degrading bacteria from the deep subsurface of the Homestake gold mine, Lead, South Dakota, USA. Journal of Industrial Microbiology and Biotechnology, Vol. 36, No. 4, 585-598, 2009.

[32] S.K. Tai, H.P.P. Lin, J. Kuo, J.K. Liu. Isolation and characterization of a cellulolytic Geobacillus thermoleovorans $\mathrm{T} 4$ strain from sugar refinery wastewater. Extremophiles, Vol. 8, No. 5, 345-349, 2004.

[33] D. Deka, P. Bhargavi, A. Sharma, D. Goyal, M. Jawed, A. Goyal. Enhancement of cellulase activity from a new strain of Bacillus subtilis by medium optimisation and analysis with various cellulosic substrates. Enzyme Research, Vol. 2011, Article ID 151656, 8 pages, 2011.(In press)

[34] J.A. Howell, M. Manget. Enzyme deactivation during cellulose hydrolysis. Biotechnology and Bioengineering, Vol. 20,847-863, 1978. 